\title{
Statyba
}

\section{HEAT DEMAND FOR HEATING APARTMENT BUILDINGS}

\section{J. Karbauskaitė \& V. Stankevičius}

To cite this article: J. Karbauskaitè \& V. Stankevičius (2000) HEAT DEMAND FOR HEATING APARTMENT BUILDINGS, Statyba, 6:5, 366-370, DOI: 10.1080/13921525.2000.10531615

To link to this article: https://doi.org/10.1080/13921525.2000.10531615

册 Published online: 26 Jul 2012.

Submit your article to this journal

山 Article views: 64 


\title{
GYVENAMŲJŲ NAMŲ FAKTINIO ŠILUMINĖS ENERGIJOS POREIKIO SULYGINIMAS SU PROJEKTINE ŠILDYMO SISTEMU GALIA
}

\author{
J. Karbauskaitė, V. Stankevičius \\ Lietuvos architektūros ir statvbos institutas
}

\section{Ivadas}

Lietuvoje gyvenamasis fondas sudaro apie $73 \mathrm{mln} . \mathrm{m}^{2}$ naudingojo ploto, iš to skaičiaus $45 \mathrm{mln}$. $\mathrm{m}^{2}$ miestuose. Mediniai būstai ir namai su karkasinèmis sienomis sudaro $27 \%$, su plytinèmis sienomis $-42 \%$, stambiaplokštè statyba $-27,4 \%$ ir kitụ konstrukcijų - 3,6\%. Iki $1992 \mathrm{~m}$. pastatyti pastatai buvo suprojektuoti pagal buvusios SSRS normas SN ir T II-3-79, ,Statybinė šiluminė technika“. Pagal šių normu reikalavimus sienų šilumos perdavimo koeficientas $U$ buvo $1,4-0,8 \mathrm{~W} /\left(\mathrm{m}^{2} \cdot \mathrm{K}\right)$, perdangu $1,0-0,7 \mathrm{~W} /\left(\mathrm{m}^{2} \cdot \mathrm{K}\right)$ ir stogy $0,8-0,5 \mathrm{~W} /\left(\mathrm{m}^{2} \cdot \mathrm{K}\right)$. $1992 \mathrm{~m}$. buvo patvirtintos RSN 143-92 „Pastatu atitvarų šiluminè technika“. Pagal šių normų reikalavimus daugiasluoksnèms sienoms (tankis daugiau kaip $200 \mathrm{~kg} / \mathrm{m}^{2}$ ) šilumos perdavimo koeficientas $U$ buvo $0,3 \mathrm{~W} /\left(\mathrm{m}^{2} \cdot \mathrm{K}\right)$, sutapdintiems stogams $0,22 \mathrm{~W} /\left(\mathrm{m}^{2} \cdot \mathrm{K}\right)$, pastogès perdangai $0,21 \mathrm{~W} /\left(\mathrm{m}^{2} \cdot \mathrm{K}\right)$. Nuo $1999 \mathrm{~m}$. patvirtintas statybos techninių normụ reglamentas STR 2.05.01:1999 „Pastatų atitvaru šiluminé technika" [1]. Jis parengtas pagal CEN ir ISO standartų reikalavimus. Pastatu atitvaru šilumos perdavimo koeficientai normuojami atskirai šioms pastatų grupéms: gyvenamiesiems pastatams, visuomeninès paskirties ir pramonès statiniams. Gyvenamujjų namų išorinių sienų šilumos perdavimo koeficiento $\mathrm{W} /\left(\mathrm{m}^{2} \cdot \mathrm{K}\right)$ normine verte yra 0,26 , stogams $-0,18$ ir langams bei durims - 1,9.

$72 \%$ gyvenamujų namų miestuose šiluma tiekiama iš dideliụ šiluminių katilinių, 15\% - iš smulkių katiliniụ ir 13\% šildoma krosnimis [2].

Dauguma butų yra privatizuota, o šilumos tiekimo ir šildymo sistema liko ankstesnès statybos. Beveik visuose namuose yra bendri šildymo ir karšto vandens skaitikliai. Butuose yra atskiri šalto ir karšto vandens skaitikliai. Šiuo metu iškilo problema, kaip paskirstyti šiluminès energijos suvartojimą tarp butų - atskirai buto šildymui ir karštam vandeniui. Pasitaiko nemaža atvejų, kai šilumos skaitiklis yra sugedęs arba šiluminès energijos suvartojimas nereglamentuojamas dèl ivairių priežasčių. Todèl reikia nustatyti norminius poreikius - karšto vandens sąnaudas vienam gyventojui ir šiluminès energijos sąnaudas $1 \mathrm{~m}^{2}$ bendrojo (naudojamojo) buto ploto pagal pastatų aukštingumą, patalpu vidaus ir išorès temperatūrą vienam mènesiui.

Tiekiant gyvenamiesiems namams šilumą iš šilumos tinklų, pirmiausia reikia spręsti šias problemas:

1) mažinti pastatų šilumos nuostolius;

2) mažinti šiluminès energijos savikainą;

3) nustatyti mokejjimo už šiluminę energiją tvarką butams.

\section{Tyrimų tikslas}

Atlikti šiluminès energijos sąnaudu gyvenamujų namų šildymui, esant įvairiems pastato atitvarų konstrukciniams sprendimams ir aukštingumui, analizę. Šiluminès energijos sąnaudas standartiniam mènesiui (išorès temperatūra $0^{\circ} \mathrm{C}, 30,5$ paros) sulyginti su projektine pastato šildymo sistemos šilumine galia ir skaičiuojamąja verte, gauta pagal standartinę metodiką.

\subsection{Pastato skaičiuojamieji ir faktiniai (pagal skai- tiklių rodmenis) šilumos nuostoliai}

Tyrimams buvo parinkti gyvenamieji namai, kuriems šiluma tiekiama iš Kauno miesto šilumos tinklų imonès. Buvo išanalizuoti 1996-1997 ir 1998-1999 metụ šildymo sezono šilumos suvartojimo namams apšildyti duomenys. Daugumos tiriamujų gyvenamujų namų plotas sudarè nuo 1000 iki $7000 \mathrm{~m}^{2}$ (1 lentelè).

Faktinis suvartotos šiluminès energijos kiekis daugelyje tirtų gyvenamujų namų yra mažesnis negu šilumos poreikis, skaičiuojamas pagal šiluminę šildymo 
sistemos galią. Ši tendencija ypač ryški mažaaukščiuose namuose, kuriu naudingasis plotas yra iki $500 \mathrm{~m}^{2}$ (1 pav.). Faktinis šilumos suvartojimas šiuose namuose yra perpus ir daugiau kartu mažesnis negu šilumos poreikis pagal apskaičiuotą šildymo sistemos galią. Nuo 2000 iki $6000 \mathrm{~m}^{2}$ naudingojo ploto turintiems gyvenamiesiems namams skirtumas tarp skaičiuojamojo šilumos poreikio, apskaičiuoto pagal šildymo sistemos galią, ir faktinio šiluminès energijos kiekio atskiruose namuose sudaro iki $70 \%$ (2 pav.).

1 lentelè. Tiriamuju gyvenamujų namų charakteristika

Table 1. Characteristics of buildings under analysis

\begin{tabular}{|c|c|c|}
\hline $\begin{array}{c}\text { Vidutinis šildomasis } \\
\text { plotas, } \mathbf{m}^{2}\end{array}$ & Namu skaičius & $\begin{array}{c}\text { \% nuo bendro } \\
\text { namu skaičiaus }\end{array}$ \\
\hline 250 & 275 & 14 \\
\hline 750 & 85 & 4 \\
\hline 4000 & 1550 & 82 \\
\hline Iš viso & 1910 & \\
\hline
\end{tabular}

Gyvenamuosiuose namuose, kurie turi nuo $1000 \mathrm{iki}$ $7000 \mathrm{~m}^{2}$ naudingojo ploto, skirtumas tarp faktinio šiluminès energijos kiekio ir apskaičiuoto pagal šildymo sistemos šiluminę galią parodytas 3 pav.

Skirtingais mènesiais gyvenamujjụ namų su tam tikru skirtumu procentas skiriasi, pavyzdžiui, $1999 \mathrm{~m}$. sausio mènesi namai su $20-50 \%$ skirtumu sudare $39 \%$ nuo viso tiriamuju namų skaičiaus, o kovo mènesi $63,6 \%$. Tai rodo, kad patalpu vidaus temperatūrai turi itakos saulès radiacija ir vidiniai šilumos išsiskyrimai, i kuriuos, nustatant šildymo sistemos šiluminę galią, nebuvo atsižvelgta.

Metinis šilumos suvartojimas gyvenamujų namų šildymui priklauso nuo šildomojo ploto dydžio (l pav. 1 kreivè). Tai paaiškinama tuo, kad mažesni pastatai šildomojo ploto vienetui turi daugiau išoriniu atitvarų.

\section{2. Šilumos poreikio gyvenamuosiuose namuose ana- lizè}

Tolesniam nagrinèjimui pasirinkti gyvenamieji namai ir jų šiluminiai parametrai pateikti 2, 3 ir 4 lentelèse. Natūriniais tyrimais buvo nustatomi tikslūs atitvarų kiekiai, patalpų panaudojimo pasikeitimai, šiluminio

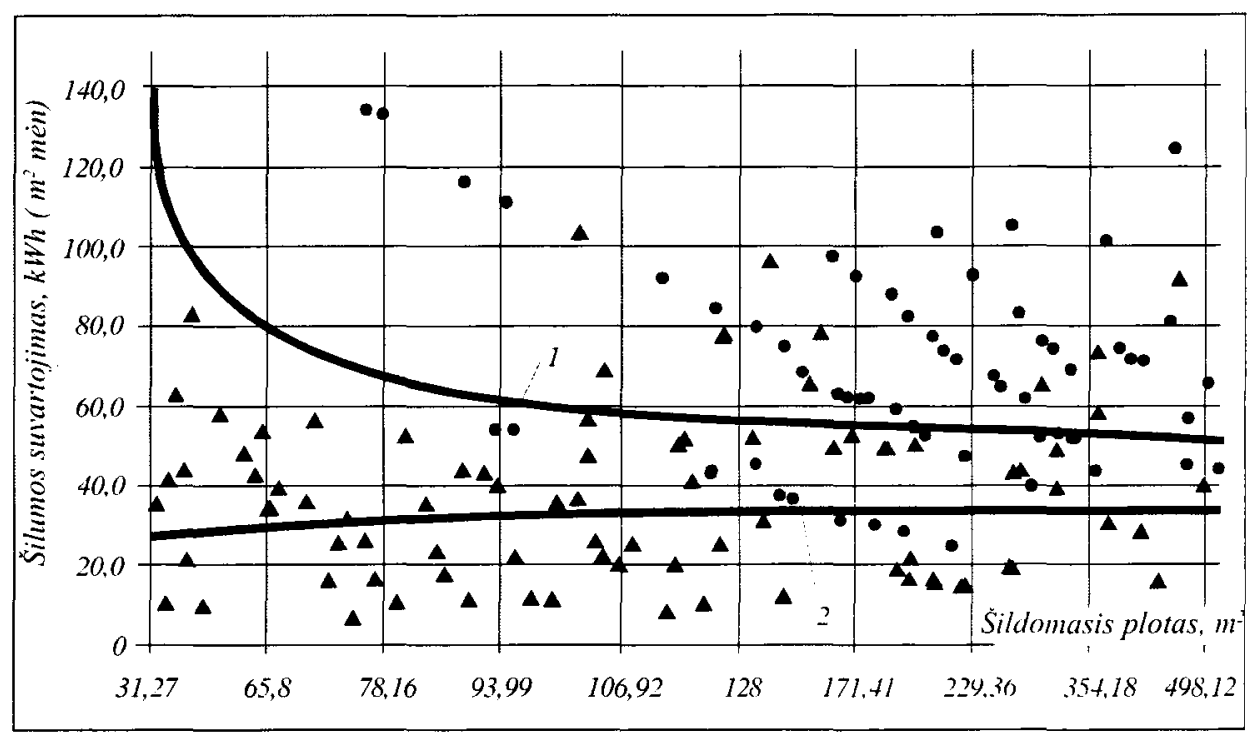

1 pav. Šilumos suvartojimas gyvenamuosiuose namuose, perskaičiuotas i vidutines ménesio temperatūras pagal pastato šildymo sistemos galia ir faktinius suvartotus kiekius prilyginant prie šildymo sezono standartinio mènesio vidutinès temperatūros $\left(-0,2^{\circ} \mathrm{C}\right)$ ir trukmès $\left(30,5\right.$ paros), kai šildomasis plotas iki $7000 \mathrm{~m}^{2}$ (Kaunas, 199701 ir 1998 01): - - šilumos poreikis pagal šildymo sistemos galią; $\boldsymbol{\Delta}$ - faktinis šilumos suvartojimas 199701 ; 1 kreivè - apibendrinta šilumos poreikio, apskaičiuoto pagal pastato šildymo sistemos galią. priklausomybé nuo šildomojo ploto; 2 kreivẻ apibendrinta faktinio šilumos suvartojimo priklausomybè nuo šildomojo ploto

Fig 1. Design and real heat consumption in apartment houses, recalculated into the standard month (average temperature conditions of heating season and duration of 30,5 days: 1 - design heat consumption, $\boldsymbol{\Delta}$ - real heat consumption in January of 1997, 1 - design heat consumption, 2 - real heat consumption 


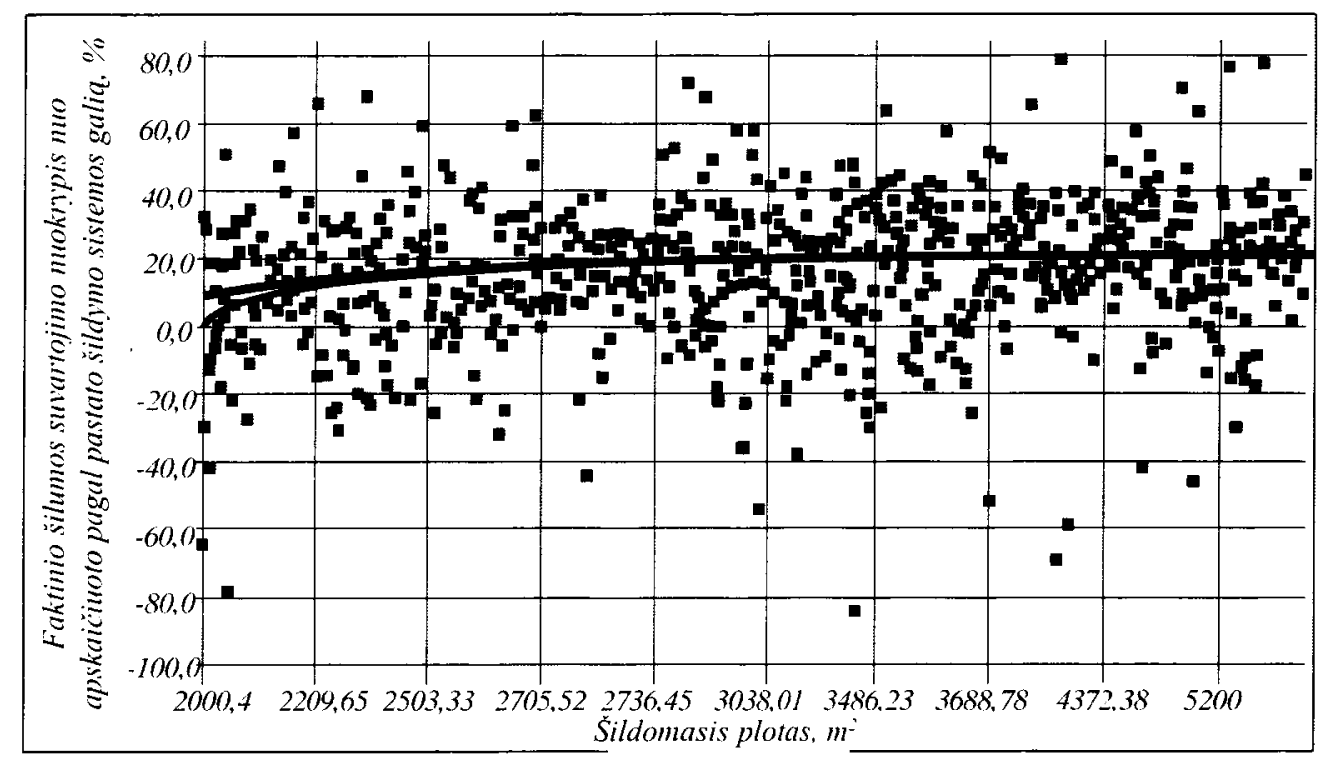

2 pav. Gyvenamujų namų faktinio suvartoto šiluminès energijos kiekio palyginimas su projektiniu šiluminès energijos poreikiu, perskaičiavus $i$ vidutines šildymo laikotarpio klimato sąlygas (Kauno m., 1999 01)

Fig 2. Difference between real heat consumption and heat demand, in $\%$, when recalculating into the standard month conditions (Kaunas, 1999 01)

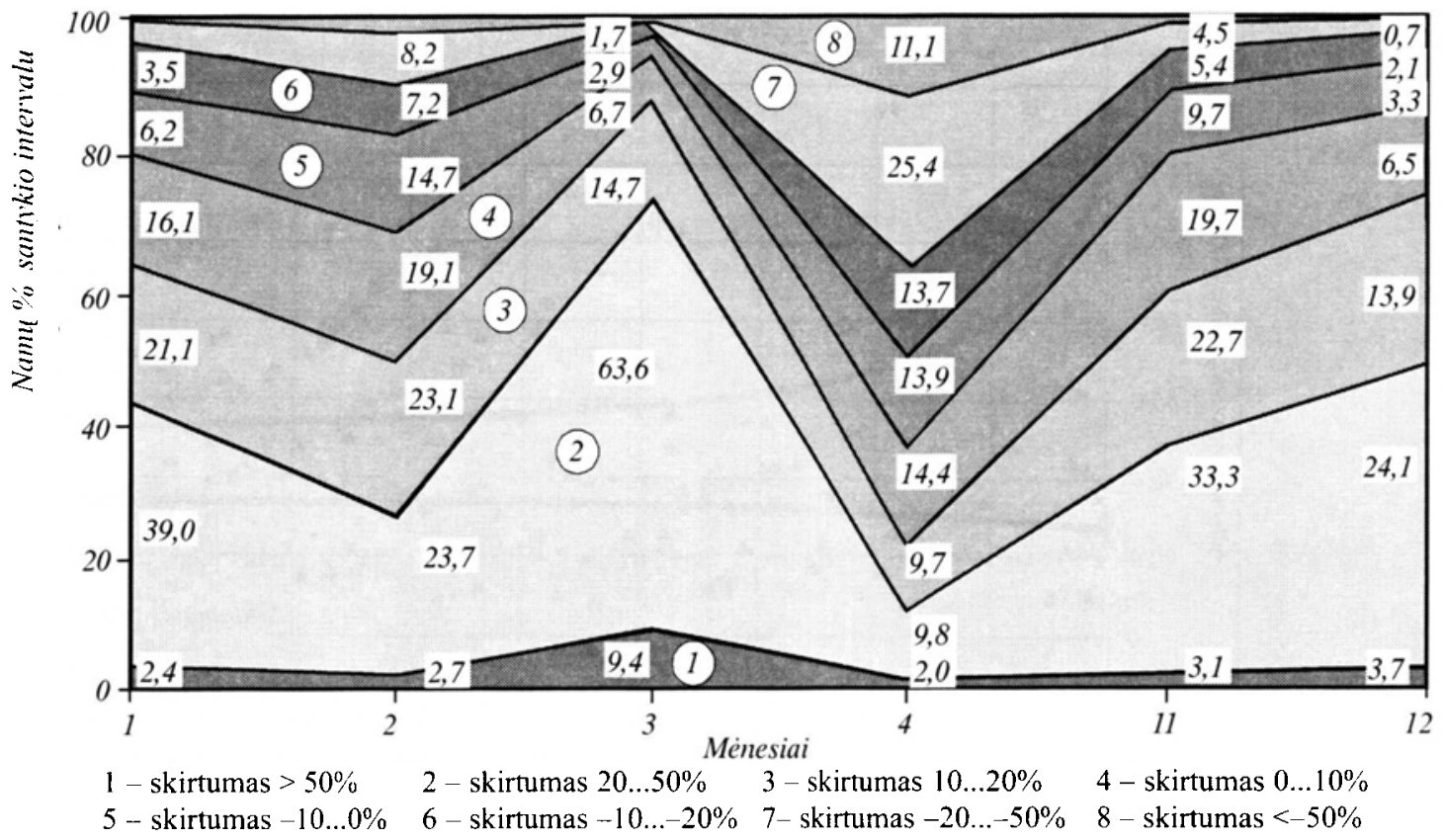

3 pav. Šilumos suvartojimo pagal šildymo sistemos galią ir faktinio šilumos suvartojimo gyvenamuosiuose namuose santykis, \%, kai šildomasis plotas 1000-7000 $\mathrm{m}^{2}$ (1997 m.)

Fig 3. Involute by months of difference ranges between heat demand and real heat consumption in apartment buildings 
2 lentelè. Gyvenamieji namai, kuriuose šiluminès energijos šildymui suvartojama daugiau, negu apskaičiuota pagal šildymo sistemos galią

Table 2. Apartment buildings with heat consumption higher than design heat demand

\begin{tabular}{|c|c|c|c|c|c|c|}
\hline Adresas & $\begin{array}{l}\text { Plotas, } \\
\mathrm{m}^{2}\end{array}$ & $\begin{array}{c}Q_{\max } \\
\mathrm{Gcal} / \mathrm{h}\end{array}$ & $\begin{array}{l}Q_{\text {fakr }}, \\
\text { Gcal }\end{array}$ & $\begin{array}{l}q_{\text {projmenn. }}, \\
\mathrm{kWh} / \mathrm{m}^{2}\end{array}$ & $\begin{array}{c}q_{\text {fakimen. }}, \\
\mathrm{kWh} / \mathrm{m}^{2}\end{array}$ & $\begin{array}{c}D q \\
\%\end{array}$ \\
\hline Šv. Gertrūdos g. 39 & 670,52 & 0,02 & 22,98 & 15,62 & 53,61 & $-243,19$ \\
\hline Laisvès al. 50 & 208,4 & 0,01 & 9,32 & 25,13 & 69,96 & $-178,38$ \\
\hline Donelaičio g. 61 & 371,77 & 0,02 & 18,01 & 28,17 & 75,78 & $-168,97$ \\
\hline Donelaičio g. 63 & 684,2 & 0,04 & 32,19 & 30,62 & 73,60 & $-140,37$ \\
\hline Vilniaus g. 41 & 515,72 & 0,04 & 31,1 & 40,62 & 94,33 & $-132,23$ \\
\hline Kovo 11 -osios g. 3 & 907,8 & 0,05 & 35,98 & 28,85 & 62,00 & $-114,93$ \\
\hline Vilniaus g. 60 & 224,52 & 0,01 & 7,14 & 23,33 & 49,75 & $-113,26$ \\
\hline T. Masiulio g. 2 & 1608,96 & 0,09 & 63,57 & 29,30 & 61,80 & $-110,97$ \\
\hline Nemuno g. 26-26a & 464,68 & 0,03 & 20,99 & 33,81 & 70,66 & $-108,98$ \\
\hline Maironio g. 14 & 1055,54 & 0,05 & 34,75 & 24,81 & 51,50 & $-107,59$ \\
\hline Laisvès al. 23 & 510,1 & 0,03 & 20,47 & 30,80 & 62,77 & $-103,80$ \\
\hline Jankaus g. 3 & 383,62 & 0,02 & 13,6 & 27,30 & 55,46 & $-103,11$ \\
\hline
\end{tabular}

3 lentelè. Gyvenamieji namai, kuriuose šiluminès energijos šildymui suvartojama tiek, kiek numatyta pagal šildymo sistemos galią

Table 3. Apartment buildings with heat consumption, near the design heat demand

\begin{tabular}{|l|c|c|c|c|c|c|}
\hline \multicolumn{1}{|c|}{ Adresas } & $\begin{array}{c}\text { Plotas, } \\
\mathrm{m}^{2}\end{array}$ & $\begin{array}{c}Q_{\text {max }}, \\
\mathrm{Gcal} / \mathrm{h}\end{array}$ & $\begin{array}{c}Q_{\text {fakr, }} \\
\text { Gcal }\end{array}$ & $\begin{array}{c}q_{\text {projmin. }}, \\
\mathrm{kWh} / \mathrm{m}^{2}\end{array}$ & $\begin{array}{c}q_{\text {faktminn., }}, \\
\mathrm{kWh} / \mathrm{m}^{2}\end{array}$ & $\begin{array}{c}D q, \\
\%\end{array}$ \\
\hline Kovo 11-osios g. 130a & 3482,18 & 0,25 & 84,95 & 37,60 & 38,16 & $-1,49$ \\
\hline Baltijos g. 18 & 2803,15 & 0,18 & 61,07 & 33,63 & 34,08 & $-1,34$ \\
\hline Riomerio g. 6 & 731,28 & 0,07 & 23,72 & 50,13 & 50,74 & $-1,21$ \\
\hline
\end{tabular}

4 lentelè. Gyvenamieji namai, kuriuose šiluminès energijos suvartojama mažiau, negu numatyta pagal šildymo sistemos galią

Table 4. Apartment buildings with heat consumption, less than the design heat demand

\begin{tabular}{|c|c|c|c|c|c|c|}
\hline Adresas & $\begin{array}{l}\text { Plotas, } \\
\mathrm{m}^{2}\end{array}$ & $\begin{array}{c}Q_{\max } \\
\mathrm{Gcal} / \mathrm{h}\end{array}$ & $\begin{array}{l}Q_{\text {fakr }} \\
\text { Gcal }\end{array}$ & $\begin{array}{c}q_{\text {projmen. }}, \\
\mathrm{kWh} / \mathrm{m}^{2}\end{array}$ & $\begin{array}{l}q_{\text {faktminen. }} \\
\mathrm{kWh} / \mathrm{m}^{2}\end{array}$ & $\begin{array}{c}D q \\
\%\end{array}$ \\
\hline Baltu pr. 67 & 5254,34 & 0,33 & 51,76 & 32,89 & 15,41 & 53,15 \\
\hline Šarkuvos g. 3 & 5200,39 & 0,36 & 59,92 & 36,25 & 18,02 & 50,29 \\
\hline Plechavičiaus g. 4 & 5044,66 & 0,55 & 87 & 57,10 & 26,98 & 52,75 \\
\hline Baltụ pr. 125 & 5031,68 & 0,32 & 50,95 & 33,31 & 15,84 & 52,44 \\
\hline Baltụ pr. 179 & 5012,6 & 0,32 & 35,33 & 33,43 & 11,03 & 67,02 \\
\hline Valančiaus g. 5 & 434,21 & 0,05 & 7,73 & 60,31 & 27,85 & 53,82 \\
\hline Putvinskio g. 17 & 403,84 & 0,06 & 9,28 & 77,81 & 35,95 & 53,80 \\
\hline Muitinès g. 11 & 399,41 & 0,03 & 1,88 & 39,34 & 7,36 & 81,28 \\
\hline
\end{tabular}

Pastabos: 2, 3 ir 4 lentelèje nurodyti pastatai priklauso būdingoms tvirtų pastatų grupèms. 
mazgo būklè ir kt. Buvo patikslinti namı̨ šilumos nuostoliai standartiniam mènesiui. Taip pat palygintos projektinès ir faktinès šilumos nuostolių vertés.

Normaliai eksploatuojamuose namuose su kokybiškomis atitvaromis, vidutinès kokybès langais ir normalia apšildymo sistema faktinis šiluminès energijos suvartojimas atitinka projektini.

Gyvenamuosiuose namuose, kurių šilumos faktiniai nuostoliai žymiai mažesni negu projektiniai, dažniausiai oro temperatūra būna apie $16^{\circ} \mathrm{C}$, patalpose yra elektrinès viryklès maistui gaminti ir istiklinta dauguma balkonų. Šiuose namuose nèra specialaus naudojimo patalpu.

\section{Išvados}

1. Faktinis šilumos suvartojimas žymiai skiriasi nuo projektinio, apskaičiuoto pagal šildymo sistemos galią. Todèl gyventojams atsiskaitant su šilumos tiekèjais už suvartotą šilumos kieki, apskaičiuotą pagal šildymo sistemos galią, galimi dideli nuokrypiai nuo realaus suvartoto šilumos kiekio.

2. Namai, kuriụ šildymui faktinès šilumos sạnaudos yra $50 \%$ didesnés negu projektinès, apskaičiuotos pagal šildymo sistemos šiluminę galią, sudaro 5-10\%.

3. Namai, kurių šildymui faktinès šilumos sąnaudos yra iki 50\% mažesnès negu projektinès, apskaičiuotos pagal šildymo sistemos šiluminę galią, sudaro iki $10 \%$. Išimti sudaro mažaaukščiai namai, kurių naudingasis plotas yra iki $500 \mathrm{~m}^{2}$, šių namu yra nuo 25 iki $50 \%$.

4. Daugumoje daugiaaukščiu pastatų projektinis šiluminès energijos poreikis, apskaičiuotas pagal šildymo sistemos galią, yra nuo 20 iki $50 \%$ didesnis negu faktinis. Visuose šiuose namuose šildymas yra reguliuojamas, dauguma gyventojų turi elektrines virykles, balkonai istiklinti.

5. Detalesnei gyvenamuju namų energijos apskajtai reikia itteisinti namo energetini pasą.

\section{Literatūra}

1. STR 2.05.01:1999. Pastatų atitvaru šiluminé technika / Aplinkos ministerija. Vilnius, 1999. 133 p.

2. R. Pikutis, V. Stankevičius. Pastatu atitvaru renovacija. Vilnius: Statybos literatūra, 1999. 135 p.

Iteikta 20000705

\section{HEAT DEMAND FOR HEATING APARTMENT BUILDINGS}

\section{J. Karbauskaitė, V. Stankevičius}

Summary

In this paper the results of statistic analysis of heat consumption in apartment heating systems for Lithuania are discussed. Kaunas district heating system data are used for the analysis. Total sum of buildings involved is about 1900 , including 1550 with the average heated area of $4000 \mathrm{~m}^{2}$. It has been established that real heat consumption in apartment buildings is less than the design heat demand (Fig 1), especially in small buildings (Fig 2). The distribution of monthly differences is presented in Fig 3. The difference during months does not depend on average outdoor temperature, but it could be caused by temperature fluctuations and solar radiation. It is quite important to determine the reasons of different heat consumption in buildings. For this purpose 20 dwelling houses of various design and building period, with various energy consumption problems have been selected for more detailed energy audit. Volumes of external building elements, changes in destination of premises, heated area have been estimated as well as the state of heat supply sub-station equipment. According to the data obtained, the energy consumption was determined for standard month at mean indoor and outdoor climate values. The results are compared with real energy consumption in the selected buildings and design values. It has been established that the inadequacies in exceeded energy consumption over design values are mostly caused by incorrect heated area registration and premises destination change, in a less range by absence of maintenance, eg broken outside doors, damaged roofs etc. Energy consumption in dwelling houses with design indoor temperature and normal maintenance level usually is near to the design value or less up to $10 \%$. In dwelling houses, in which energy consumption is defined as being of less design value, some energy saving measures are applied, eg temperature in spaces is lowered up to $16^{\circ} \mathrm{C}$, about half of balconies are glassed, electric stoves for cooking are installed as additional heat source. Such apartment buildings, as a rule, do not have premises of other destination. By such means near $40 \%$ of heat is saved.

Jūratė KARBAUSKAITE். Doctor. Institute of Architecture and Construction. Building Thermal Physics Laboratory. Tunelio g. 60, LT-3035 Kaunas. Lithuania. E-mail: silfiz@asi.lt, jukarb(c)asi.lt.

Author and co-author of more than 50 reports and papers, including 2 building codes. Research interests: energy saving in buildings, heat and mass transfer in building constructions, indoor climate.

Vytautas STANKEVIČIUS. Doctor Habil, Professor. Institute of Architecture and Construction. Tunelio g. 60, LT-3035 Kaunas, Lithuania. E-mail: silfiz(uasi.It.

Doctor (1966). Doctor Habil (1991). Professor (1995). Author of 182 papers, including 115 scientific (47 of them in foreign issues), 3 patents, 2 monographs, 2 manuals for higher schools, 15 building normative documents. 